\title{
Passive smoking: Absorption by non-smokers of carbon monoxide from room-air polluted by tobacco smoke*
}

\author{
M. A. H. RUSSELL \\ B.M., M.R.C.P., D.P.M.
}

\author{
P. V. COLE \\ M.B., F.F.A., R.C.S.
}

Institute of Psychiatry, London, S.E.5 and St Bartholomew's Hospital, London, E.C.1

\begin{abstract}
Summary
Twenty subjects spent a mean of 78 min seated in an unventilated smoke-filled room of approximately $43 \mathrm{~m}^{3}(15 \times 12 \times 8 \mathrm{ft})$. The smoke was produced by burning and smoking eighty cigarettes and two cigars. The average ambient carbon monoxide (CO) concentration was $38 \mathrm{ppm}$. Blood samples taken before and after the exposure showed an increase in carboxyhaemoglobin $(\mathrm{COHb})$ in all subjects without exception $(P<0.001)$. The $\mathrm{COHb}$ of the twelve nonsmokers increased from a mean of $1.6 \%$ to $2.6 \%$ $(P<0.001)$, while the six cigarette smokers, all inhalers, besides having significantly higher initial levels $(P<0.001)$ also showed a greater increase from a mean of $5.9 \%$ to $9.6 \%(P<0.001)$. The two cigar smokers, one an inhaler, the other a non-inhaler, showed respective $\mathrm{COHb}$ changes similar to the cigarette smokers and non-smokers. The mean increase of $1 \% \mathrm{COHb}$ among the non-smokers was similar to the mean increase for the smokers of $0.7 \%$ for each cigarette smoked, suggesting that the amount of $\mathrm{CO}$ which the non-smokers absorbed by passive smoking was about the same as would be expected if they had actively smoked and inhaled one cigarette.
\end{abstract}

\section{Introduction}

The level of venous blood carboxyhaemoglobin $(\mathrm{COHb})$ in humans depends mainly on the rate of endogenous carbon monoxide $(\mathrm{CO})$ production, the concentration of exogenous $\mathrm{CO}$ in the inspired air and alveolar ventilation (Coburn, Forster \& Kane, 1965). It is well established that tobacco smoke contains as much as $5 \% \mathrm{CO}$ and that smoking increases blood COHb (Lawther \& Commins, 1970; Surgeon General, 1972). Attention has recently been directed at the possibility that tobacco smoke may also be a source of $\mathrm{CO}$ contamination for non-smokers in the vicinity of smokers especially if the exposure is prolonged and occurs in poorly ventilated confined places (Srch, 1967; von Harke, 1970; Godber, 1971). Persistently raised COHb levels may be hazardous to

\footnotetext{
* This article is reproduced from the Lancet (1973) i, 576, by kind permission of the Editor.
}

health (Surgeon General, 1972; Astrup, 1972). We have attempted to assess the degree to which nonsmokers are put at risk by unavoidable 'passive smoking' of air which has been polluted, not by themselves, but by smokers.

\section{Material and methods}

Twenty-one research and clerical colleagues volunteered to provide blood specimens before and after spending at least $1 \mathrm{hr}$ in a smoke-filled room. The conditions were deliberately made worse than would be likely to be encountered in natural social situations. The experimental room was approximately $43 \mathrm{~m}^{3}(15 \times 12 \times 8 \mathrm{ft})$. Ventilators were switched off and all windows closed. Before subjects entered the room it was 'smoked up' by leaving thirty cigarettes (Piccadilly tipped) to burn in ashtrays. During the experiment the smokers smoked thirty-two cigarettes and two cigars; a further eighteen cigarettes were left to burn in ashtrays. During the average time of $78 \mathrm{~min}$ spent in the experimental room, subjects remained seated in the same place. The exposure was extremely unpleasant causing eyes to burn and water. For most subjects it was worse than they could recall having tolerated on normal social occasions.

At $18 \mathrm{~min}$ and again at $53 \mathrm{~min}$ after the subjects had entered the room (mean entry for all subjects), samples of room air were collected at heights of

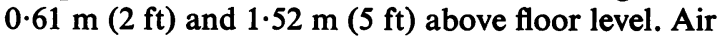
samples were collected into special gas-sampling bags (Hawkins, 1967) and analysed for CO with a Hartmann and Braun infra-red analyser (URAS 2). The zero point of the instrument was set with $\mathrm{O}^{2}$-free nitrogen and the span with 200 ppm CO in air (Rank Precision Industries). All samples were dried with magnesium perchlorate. The $\mathrm{CO}$ concentration of the first two samples was $37.0 \mathrm{ppm}(0.61 \mathrm{~m})$ and $32.5 \mathrm{ppm}(1.52 \mathrm{~m})$. For the second two samples, it was $41.8(0.61 \mathrm{~m})$ and $41.3(1.52 \mathrm{~m})$ giving an approximate average for the experiment of $38 \cdot 2$ ppm.

Venous blood samples were collected into heparinized syringes at an average of $10 \mathrm{~min}$ before entry 
and $12 \mathrm{~min}$ after leaving the experimental room. The syringes were capqed and stored in ice. The analysis for $\mathrm{COHb}$ was done on the same day using an IL 182 CO-Oximeter. Accuracy of this method was checked by comparison with the spectrophotometric method of Commins \& Lawther (1965) and Lily, Cole \& Hawkins (1972). The correlation between the two methods was 0.99 for thirty-three specimens over the range of $0-11.7 \% \mathrm{COHb}$. The reproducibility was checked by taking four measurements of each of four specimens which gave the following means \pm S.E., $0.92 \% \pm 0.03 ; 3.58 \% \pm 0.03 ; 5.60 \%$ $\pm 0.8 ; 88 \% \pm 0.05$. Thus, over the range employed the $95 \%$ confidence limits of the reproducibility of the $\mathrm{CO}-\mathrm{Oximeter}$ lie within $0 \cdot 1 \% \mathrm{COHb}$.

\section{Results}

The initial $\mathrm{COHb}$ levels (see Table 1 and Fig. 1) were much higher in the smokers (mean $5.9 \%$ ) than in the non-smokers (mean 1.6\%) and the difference is statistically significant $(\mathrm{t}=5.8, \mathrm{df}=17, P<0.001)$. The initial $\mathrm{COHb}$ level of individual smokers was related to their usual cigarette consumption $(r=0 \cdot 80$, $P<0.05)$ and to the number of cigarettes smoked on the morning before the experiment $(\mathrm{r}=0.79, P<0.05)$.

After the experimental exposure, $\mathrm{COHb}$ was increased in all subjects without exception $(t=5 \cdot 01$, $\mathrm{df}=17, \quad P<0.001)$. The $\mathrm{COHb}$ of non-smokers increased from the mean of $1.6 \%$ to $2.6 \%(\mathrm{t}=5.9$, $\mathrm{df}=11, P<0.001)$ while the smokers showed a substantially larger increase from a mean of $5.9 \%$ to $9.6 \%$. The greater mean increase of the smokers compared with the non-smokers $(3.6 \%$ vs $1.03 \%)$ is statistically significant $(\mathrm{t}=5 \cdot 1, \mathrm{df}=16, P<0.001)$. Among the smokers the rise in $\mathrm{COHb}$ was only modestly, but not significantly, related to the number of cigarettes smoked during the experiment $(r=0.55$, $P<0 \cdot 1)$ but there was a stronger relation to the length of time spent in the experimental room $(r=0.85$, $P<0.05$ ). Surprisingly, the duration of exposure in the experimental room did not emerge as a significant factor determining the variation in $\mathrm{COHb}$ rise in the case of the non-smokers $(r=-0.38$, n.s. $)$.

The rise in $\mathrm{COHb}$ for each smoker was adjusted to the increase per cigarette smoked during the experiment, giving a mean increase for the six smokers of $0.7 \% \mathrm{COHb}$ (range $0.31-0.97$, S.D. 0.24 ) for each cigarette smoked. (See Fig. 2.) This is about the same as the mean increase of $1.03 \% \mathrm{COHb}$ for the non-smokers and suggests that the amount of $\mathrm{CO}$ that the non-smokers absorbed by passive smoking was roughly equivalent to the amount taken in by the smokers from one cigarette.

\section{Discussion}

The results indicate unequivocally that in circumstances of poor ventilation non-smokers do absorb

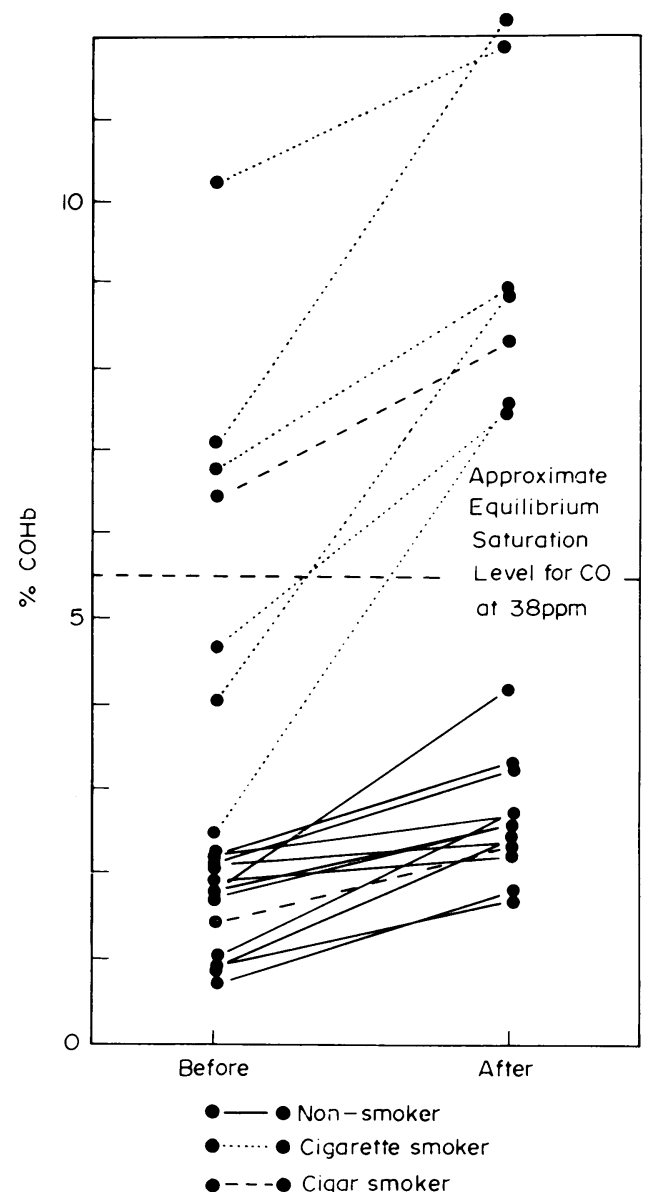

FIg. 1. Changes in Blood $\mathrm{COHb}$ after spending a mean of 78 minutes in a smoke-filled room containing a mean of $38 \mathrm{ppm} \mathrm{CO}$.

$\mathrm{CO}$ from tobacco smoke produced when other people smoke. The rise in blood $\mathrm{COHb}$ levels of these twelve non-smokers from a mean of $1.6 \%$ to $2.6 \%$ after an average of $79 \mathrm{~min}$ exposure to smoke-filled room-air containing about $38 \mathrm{ppm}$ of $\mathrm{CO}$ accords well with two similar studies that are to be found in the German literature. In one, Srch (1967), the smoking of ten cigarettes over a period of $62 \mathrm{~min}$ in an enclosed car produced a $\mathrm{CO}$ level of $90 \mathrm{ppm}$ and caused the $\mathrm{COHb}$ of two non-smokers to increase from $2 \%$ to $5 \%$, while in the other, von Harke (1970), the levels of seven non-smokers increased from a mean of $0.9 \%$ to $2.1 \%$ after they had spent about $90 \mathrm{~min}$ in a smoke-filled room containing $30 \mathrm{ppm}$ of $\mathrm{CO}$.

We have shown that the average $\mathrm{COHb}$ rise in smokers attributable to each cigarette smoked is about $0.7 \%$, which suggests that, in these admittedly extreme experimental circumstances, the amount of $\mathrm{CO}$ that the non-smokers absorbed by passive 


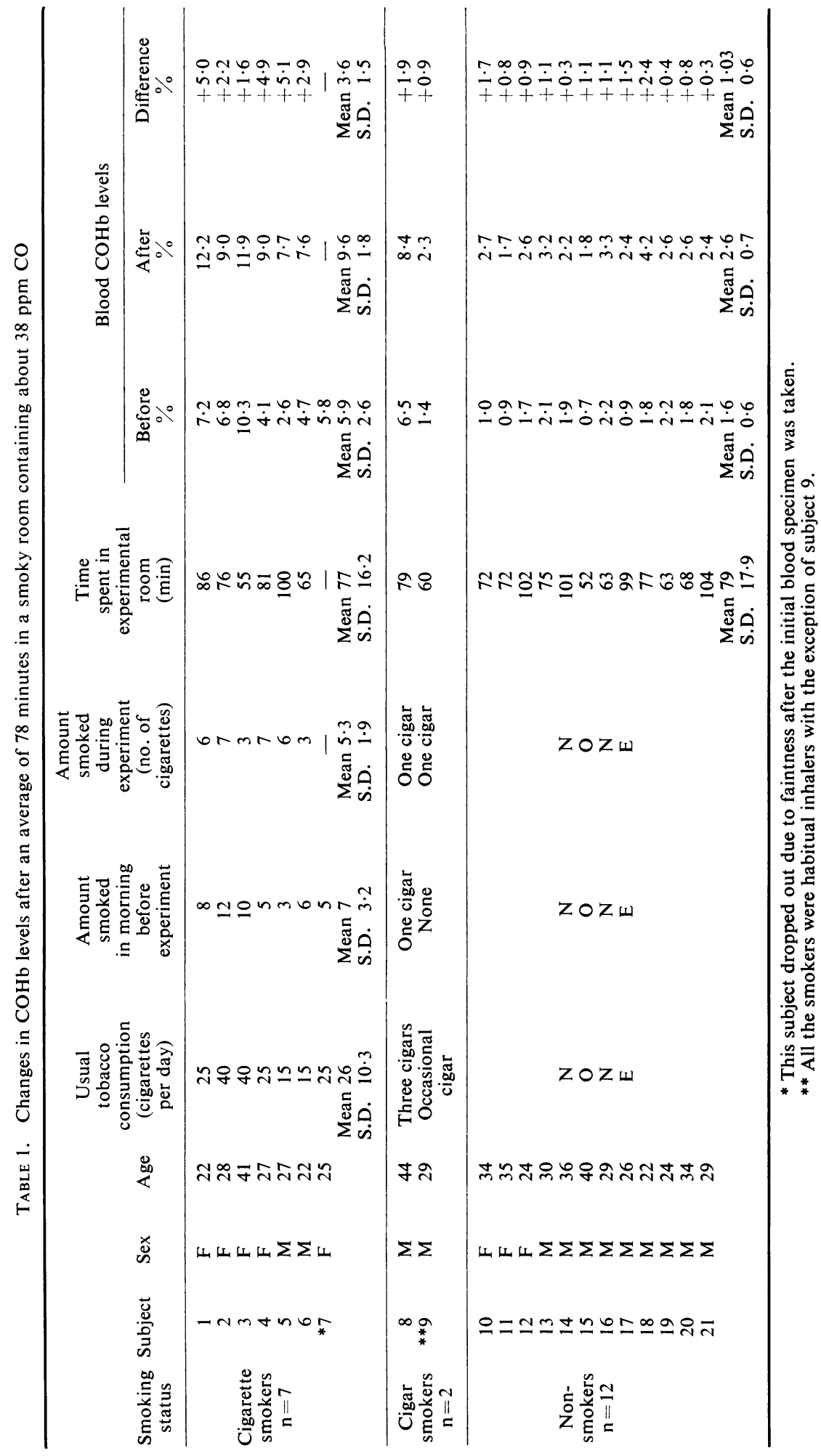




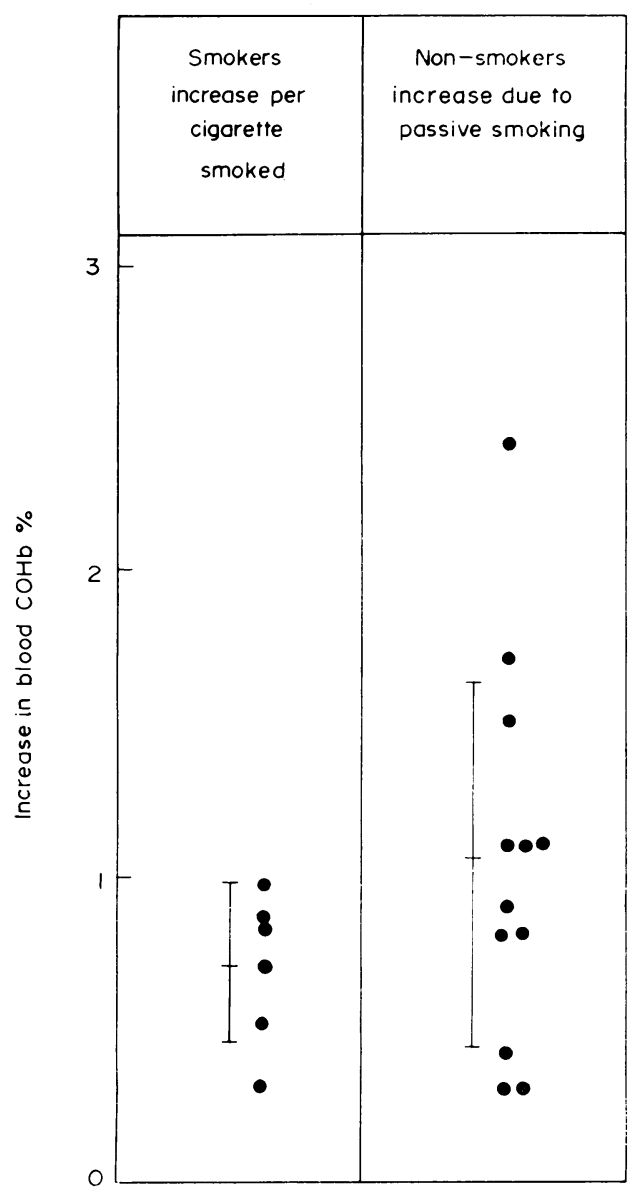

FIG. 2. Increase in $\mathrm{COHb}$ levels of non-smokers due to 'passive smoking' compared with increase in smokers per cigarette smoked. Both smokers and non-smokers spent an average of 78 minutes in the same smoky room containing a mean of $38 \mathrm{ppm} \mathrm{CO}$. Lines indicate the means \pm 1 S.D. The difference between the means is not significant $(\mathrm{t}=1 \cdot 25, \mathrm{df}=16, P>0 \cdot 1)$.

smoking was about the same as would be expected if they had actively smoked and inhaled one cigarette. It was also of the same order as a London taxi driver takes in from traffic pollution during a whole day of driving (mean $\mathrm{COHb}$ levels for non-smoking day drivers vs night drivers: $2 \cdot 31 \%$ vs $1 \cdot 04 \%$ ) (Jones, Commins \& Cernik, 1972) and similar to that absorbed by London policemen after $3 \mathrm{hr}$ of point duty (Lawther \& Commins, 1970).

A puzzling result was the absence among the nonsmokers of a significant relation between the amount of $\mathrm{CO}$ absorbed and the duration of exposure. This is unlikely to have been due to a plateau effect as even by the end of the experiment their $\mathrm{COHb}$ levels were still well below the saturation level (approximately $5.5 \%$ ) (U.S. Department of Health, Education and
Welfare, 1970) for the $38 \mathrm{ppm}$ of CO in the room. Apart from individual factors such as differences in pulmonary ventilation, part of the explanation may be accounted for by variations in $\mathrm{CO}$ concentration in different parts of the room. It has been shown that the air in the vicinity of a smoker can show transient peaks exceeding 90 ppm (Lawther \& Commins, 1970). The exceptionally large increase in $\mathrm{COHb}$ in one non-smoker (subject 18 ) could possibly be accounted for by the fact that he was sitting in the most smoky part of the room, between the two cigar smokers.

In the case of the smokers it is difficult to explain why the length of time spent in the experimental room had a stronger relation to the rise in $\mathrm{COHb}$ level than did the number of cigarettes smoked during the experiment. The $\mathrm{COHb}$ level of all the smokers ended up well above the $5.5 \%$ equilibrium saturation level for the $\mathrm{CO}$ in the room. Above this level the rise in $\mathrm{COHb}$ could only have been mediated by smoking; indeed, without smoking it would gradually fall. Part of the explanation may lie in variation in the degree of inhalation. They were reluctant to smoke as much as they did and did so only because they had been so instructed. The smokers who followed the instructions conscientiously and smoked more may have consequently inhaled less while those who disregarded the instructions may have smoked less but continued to inhale as usual.

Because there were only two, the cigar smokers were not used for the analysis. However, they do demonstrate that as far as $\mathrm{CO}$ is concerned a cigar smoker who inhales differs little from cigarette smokers, while the non-inhaler had $\mathrm{COHb}$ levels identical with the non-smokers, confirming the fact that little absorption of $\mathrm{CO}$ takes place through the buccal mucosa (Surgeon General, 1972).

The experimental conditions were somewhat extreme. This degree of tobacco smoke pollution is unlikely to be encountered with any frequency in 'natural' social situations. However, the exposure time was short compared with some social situations. Even with slightly better ventilation $3-4 \mathrm{hr}$ in a smoky car or pub would almost certainly involve a non-smoker in significant passive smoking. Further work is indicated in more natural settings. Though the amounts of $\mathrm{CO}$ absorbed by passive smoking are very small compared with active smoking, there may well be appreciable long-term negative health consequences (Surgeon General, 1972; Astrup, 1972). Evidence is also beginning to accrue that subtle perceptual abilities such as visual acuity, brightness threshold, and time interval discrimination may be temporarily impaired by absorption of small amounts of $\mathrm{CO}$ at blood $\mathrm{COHb}$ levels as low as $3 \%$, Beard \& Grandstaff (1970), and three of the nonsmokers in the present experiment reached this level. Finally, there is suggestive evidence that passive 
smoking may result in absorption of other potentially hazardous components of tobacco smoke, for example, tar, nicotine, 3,4-benzpyrene and oxides of nitrogen (NO, $\mathrm{NO}_{2}$ ) (Surgeon General, 1972). It seems, therefore, that in addition to discomfort, occasional allergic reactions, nasal and conjunctival irritation, a small but real health risk is another potential consequence of passive smoking. This is an order of risk that smokers are prepared to take many times a day, but insignificant though it may be compared with active smoking it is a risk that many non-smokers may wish to avoid. They should at least have a choice.

\section{Acknowledgments}

We are grateful to the staff of the Addiction Research Unit, Institute of Psychiatry, who acted as subjects for the experiment. Thanks are also due to Upendra Patel for checking the statistical calculations and to Dr Keith Ball for helpful comments.

\section{References}

Astrup, P. (1972) Some physiological and pathological effects of moderate carbon monoxide exposure. British Medical Journal, 4, 447.

BeARD, R.R. \& GRandstafF, N. (1970) Carbon monoxide exposure and cerebral function. Annals of the New York Academy of Sciences, 174, 385.
Coburn, R.F., Forster, R.E. \& Kane, P.B. (1965) Considerations of the physiological variables that determine the blood carboxyhaemoglobin concentration in man. Journal of Clinical Investigation, 44, 1899.

Commins, B.T. \& LAwTHER, P.J. (1965) A sensitive method for the determination of carboxyhaemoglobin in a finger prick sample of blood. British Journal of Industrial Medicine, 22, 139.

GoDber, G. (1971) It can be done. In: The Second World Conference on Smoking and Health (edited by R. G. Richardson); p. 141, London.

Hawkins, L.H. (1967) Plastic bags for the collection and storage of gas samples. Journal of Science and Technology, 13, 21 .

Jones, R.D., Commins, B.T. \& Cernik, A.A. (1972) Blood lead and carboxyhaemoglobin levels in London taxi drivers. Lancet, ii, 302.

Lawther, P.J. \& Commins, B.T. (1970) Cigarette smoking and exposure to carbon monoxide. Annals of the New York Academy of Sciences, 174, 135.

Lily, R.E.C., Cole, P.V. \& HAWKins, L.H. (1972) Spectrophotometric measurements of carboxyhaemoglobin. British Journal of Industrial Medicine, 29, 454.

SRCH, M. (1967) The importance of carbon monoxide from cigarette smoking in motor cars. Deutsche Zeitschrift für die gesamte girichtliche Medizin, 60, 80 .

SURGEON GENERAL (1972) The health consequences of smoking. U.S. Department of Health, Education and Welfare.

U.S. Department of Health, Education and Welfare (1970) Air Quality Criteria for Carbon Monoxide.

VON HARKE, H.P. (1970) The problem of passive smoking. Münchener medizinische Wochenschrift, 112, 2328. 